\title{
Çocuk Hastalarda Koblasyon Tonsillektomi ve Bipolar Tonsillektominin Karşılaştırılması
}

\section{Comparison of Coblation Tonsillectomy and Bipolar Tonsillectomy in Pediatric Patients}

\author{
Secaattin Gülsen $\underline{1}$
}

\author{
1 Dr.Ersin Arslan Eğitim ve Araştırma Hastanesi KBB Kliniği, Gaziantep
}

Öz

Amaç: Tonsillektomi ameliyat sonrası ağrı şiddeti fazla olan ve çocuk hastalarda sık uygulanan cerrahi bir işlemdir. Bu çalışmada koblasyon ve bipolar teknikle tonsillektomi yapılan çocuk hastalarda ameliyat süresinin ve ameliyat sonrası ağı ve gelişen komplikasyonların karşılaştırılması amaçlandı.

Materyal ve Metod: Bu retrospektif çalışmaya yaşları 5-13 arasında değişen koblasyon $(n=37)$ ve bipolar $(n=41)$ diseksiyon teknikleri kullanılarak Mayıs 2018 ve Nisan 2019 tarihleri arasında total tonsillektomi yapılan toplam 78 hasta dahil edildi. Gruplar arasında ameliyat süresi, ameliyat sonrası ağrı şiddeti ve komplikasyonlar karşılaştırıldı.

Bulgular: Ortalama ameliyat süresi koblasyonton sillektomi yapılan grupta bipolar tonsillektomi yapılan gruba göre anlamlı derecede uzundu $(p<0.001)$. Koblasyon tonsillektomi sonrası ağrı ameliyat sonrası birinci $(p<0.001)$, ikinci $(p=0.019)$ ve üçüncü $(p=0.041)$ günlerde bipolar tonsillektomi sonrası ağıı ile kıyaslandığında anlamlı derecede daha azdı. Ameliyat sonrası kanama bipolar tonsillektomi grubuna kıyasla koblasyon tonsillektomi grubunda daha az sıklıkta gözlendi $(p=0.034)$.

Sonuç: Çocuklarda koblasyon tonsillektomi bipolar tonsillektomiye kıyasla daha uzun ameliyat sürelerine ve daha fazla maliyete rağmen ameliyat sonrası daha az ağrı ve morbiditeyle ilişkili son derece güvenli bir tekniktir.

Anahtar Kelimeler: Tonsillektomi, Ağrı, Komplikasyon, Kanama

\section{Abstract}

Background: Tonsillectomy is a common surgical procedure in pediatric patients with high intensity of postoperative pain. The aim of this study was to compare the duration of surgery and postoperative pain and complications in pediatric patients who underwent tonsillectomy with coblation and bipolar technique. Materials and Methods: This retrospective study included 78 patients who underwent total tonsillectomy between May 2018 and April 2019 using coblation $(n=37)$ and bipolar $(n=41)$ dissection techniques aged 5-13 years. Operative time, postoperative pain scores and complications were compared between the groups.

Results: Mean operative time was significantly longer in coblation tonsillectomy group than bipolar tonsillectomy group $(p<0.001)$. Mean pain scores after coblation tonsillectomy was significantly less on postoperative first $(p<0.001)$, second $(p=0.019)$ and third $(p=0.041)$ days compared to mean pain scores of patients undergoing bipolar tonsillectomy. Postoperative bleeding was less frequent in the coblation tonsillectomy group than in the bipolar tonsillectomy group $(p=0.034)$.

Conclusions: Coblation tonsillectomy in children is an extremely safe technique associated with less postoperative pain and morbidity, despite longer operating times and more cost than bipolar tonsillectomy.

Key words: Tonsillectomy, Pain, Complications, Bleeding

\section{Sorumlu Yazar $I$ Corresponding Author}

Dr. Secaattin Gülşen

Dr.Ersin Arslan Eğitim ve Araştırma Hastanesi KBB Kliniği

Eyüpoğlu Mahallesi, Hürriyet Cd. No:40, 27010 Şahinbey/Gaziantep-TÜRKIYE

Tel: (0342) 2210700

Fax: (0342) 2210142

Mobil: 5078534467

E-mail: drsecaattingulsen@gmail.com

Geliş tarihi / Received:05/07/2019

Kabul tarihi / Accepted: 25/10/2019

DOI: $10.35440 /$ hutfd.587644 


\section{Giriş}

Tonsillektomi çocuk hastalarda tıkayıcı uyku apne senromu ve/veya kronik tekrarlayıcı tonsillit nedeniyle kulak burun boğaz pratiğinde en sık uygulanan cerrahi işlemlerden biridir (1). Tonsillektomi sonrasında bulantı, kusma, oral alım bozukluğu, ağrı ve kanama gibi birçok komplikasyon görülebilmektedir (2). Tonsillektomi sonrası kanama tonsillektominin en önemli komplikasyonlarındandır ve nadiren de olsa yaşamı tehdit edebilecek şiddetle olabilir (3). Erişkin tonsillektomi hastalarında daha sık gözlemlenen postoperatif ağrı, çocuk hastalarda da yaşam kalitesini azaltan, ciddi oral beslenme bozukluklarına neden olabilen ve uzamış analjezik kullanımı gerektiren sık karşılaşılan önemli bir sorundur (4). Son zamanlarda gelişen teknoloji ile birlikte tonsillektomi ameliyatlarından sonra meydana gelebilen komplikasyonları ve morbiditeleri azaltmak adına monopolar elektrokoter, bipolar diatermi, termal welding ve koblasyon teknolojileri sıklıkla kullanılmaya başlanmışıı $(4,5)$.

Koblasyon teknolojisinde, bir radyo frekans bipolar akımı koblatör aletinin ucundaki aktif bölgede dahili yıkama sistemi sayesinde serum fizyolojik çözelti akımıyla düşük frekansta uygulanır ve böylece bir plazma alanı oluşturulur (6). Koblatör aletinin ucundaki aktif bölgede oluşan bu plazma alanı monopolar ve bipolar gibi diğer geleneksel elektrokoter sistemlere kıyasla daha düşük bir sıcaklıkta dokuyu etkili bir şekilde buharlaştırıp dokunun ayrışmasına neden olur ve aynı anda dahili bir emme sistemi ile ayrıştııılan dokunun aspirasyonunu sağlar (7). Geleneksel elektrokoter sistemlere kıyasla koblatör teknolojisi göreceli olarak daha düşük yüzey sıcaklıkları (40-60॰) ile çalışmaya olanak verir, böylece ameliyat esnasında etraf dokudaki termal hasar en aza indirgenmiş olur.

Bu retrospektif çalışmanın temel amacı çocuk hastalarda koblasyon tonsillektomi ile bipolar tonsillektomi tekniklerini ameliyat süresi, ameliyat sonrası ağrı ve kanama gibi komplikasyonlar açısından karşılaştırmaktır.

\section{Materyal ve metod}

Özel bir hastanenin ve üçüncü basamak bir hastanenin kulak burun boğaz kliniklerinde Mayıs 2018 ve Nisan 2019 tarihleri arasında rekürren tonsillit ve / veya tıkayıcı tonsil hipertrofisi nedeni ile koblasyon $(n=37)$ ve bipolar diseksiyon $(n=41)$ teknikleriyle bilateral total tonsillektomi yapılan toplam 78 hasta bu retrospektif çalışmaya dahil edilmiştir. Koblasyon ve bipolar diseksiyon tekniğiyle tonsillektomi yapılan hastalar sırasıyla grup-1 ve grup-2 olarak iki farklı gruba ayrımışlardır. Çalışmaya başlanımadan önce yerel etik kurul onayı alınmıştır ve çalışmaya katılan tüm çocuk hastaların ebeveynlerinden bilgilendirilmiş onam formu alınmıştır. Soğuk teknik tonsillektomi yapılan hastalar, plika sütürasyonu yapılan hastalar, tek taraflı tonsillektomi yapılan hastalar ve erişkin hastalar çalışmaya dahil edilmemiştir. Tüm hastalar aynı cerrah tarafından genel anestezi altında ameliyat edilmiştir.

\section{Cerrahi teknik}

Bipolar diseksiyon tonsillektomi yapılan grupta standart ekstrakapsüler sıcak diseksiyon yöntemiyle ameliyat gerçekleştirilmiş̧ir. Bipolar elektrokoter cihazının gücü 20 watt olarak ayarlanmıştır. Kanama kontrolü diseksiyon ile eş zamanlı olarak bipolar koterizasyon ile sağlanmıştır. Koblasyon tonsillektomi ise Cobator II (Smith-Nephew, London, UK) cihazı ve Evac 70 koblatör ucu kullanılarak ekstrakapsüler diseksiyon tekniğiyle yapılmıştır. Coblator II cihazı gücü ablasyon modu için 8'e koblasyon modu için 6'ya ayarlanmışıtır. Koblasyon tonsillektomi sonrası kanama odakları koblasyon modunda 1-2 saniye süresince aktif uç kanayan bölgelere dokundurulmak suretiyle hemostaz sağlanmıştır. Hastalara ameliyat esnasında analjezi için intravenöz parasetamol $(10 \mathrm{mg} / \mathrm{kg})$ uygulanmıştır. Cerrahi alana herhangibir anestezik veya analjezik ilaç uygulaması yapılmamıştır. Ameliyat sonrası dönemde kullanılmak üzere hastalara amoksisilin klavunat ve analjezi için ibuprofen reçete edilmiştir. Penisilin grubu antibiyotik alerjisi olan hastalar klaritromisin verilmiştir.

\section{Parametreler}

Hastaların cinsiyet, yaş, kilo ve cerrahi endikasyon gibi demografik ve klinik özellikleri gruplar arasında karşılaştırılmıştır. Ameliyat süresi ağız ekartörünün yerleştirilmesinden hemostaz sağlanıncaya kadar geçen süre olarak kabul edilmiştir. Hastaların ebeveynlerine taburculuk anında ameliyat sonrası 1 hafta boyunca ağrı şiddetini değerlendirmeleri için Wong Baker görsel ağrı ölçeği verilmiştir ve puanlandırmayı nasıl yapacakları hakkında bilgilendirilmiştir. Görsel ağrı ölçeğinde '10' puan en şiddetli ağrıyı ' 0 ' puan ise ağıı olmamasını temsil etmektedir. Ailelerden görsel ağrı ölçeğini her sabah analjezik ilaç almadan doldurmaları belirtilmiştir. Ameliyat sonrası 1. hafta kontrol muayenesinde görsel ağrı ölçeğindeki puanlar gruplar arasında karşılaştırımışıtır. Hastalarda ameliyat sonrası dönemde gelişen kanama, oral alım bozukluğu, dehidratasyon ve ateş gibi gelişen tüm komplikasyonlar kaydedilmiş ve karşılaş̧ıııımıştır. Ameliyat sonrası ilk 24 saatte gözlenen kanamalar primer, 24 saatten sonra meydana gelen kanamalar ise sekonder kanamalar olarak sınıflandırılmıştır.

\section{İstatiksel analiz}

Verilerin istatistiksel analizi için Windows 10 için IBM SPSS versiyon 22.0 yazııımı kullanılmıştır. Verilerin dağıIımları Kolmogorov-Smirnov testi ile kontrol edildi. Koblasyon ve bipolar tonsillektomi hastalarının demografik verileri, kategorik değişkenler için Pearson ki-kare testi ve sürekli değişkenler için bağımsız t testi kullanılarak karşılaştırıldı. Gruplar arasındaki ameliyat sonrası ağrı skorları karşılaştırması için t testi kullanıldı. \%95 güven aralığında 0.05 değerinden daha az olarak hesaplanan $P$ değeri istatistiksel olarak anlamlı kabul edildi. Sonuçlar ortalama 
\pm standart sapma (SS), ortanca (median) ve yüzde (\%) olarak sunulmuştur.

\section{Bulgular}

$\mathrm{Bu}$ retrospektif çalışmaya koblasyon $(\mathrm{n}=37)$ ve bipolar diseksiyon (41) yöntemiyle bilateral total tonsillektomi yapılan toplam 78 hasta dahil edilmiştir. Koblasyon tonsillektomi grubundaki (Grup-1) hastaların yaşları 6-12 yaş arasında ve ortalama $8.2 \pm 3.9 \mathrm{yll}$ idi. Bipolar tonsillektomi (Grup-2) yapılan hastaların ise yaşları $5-13$ yaş arasında olup ortalama $7.9 \pm 4.1$ yıl idi. Gruplar arasında yaş dağıIımı açısından anlamlı fark yoktu ( $p>0.05)$. Grup-1 deki hastaların 21'i (\% 56.8) kadın iken, 16'sı (\% 43.2) erkek idi. Grup-2 ise 22 (\% 53.7) kadın ve 19 (\% 46.3) erkek hasta içeriyordu ve cinsiyet dağılımı açısından da gruplar arasında istatistiksel olarak anlamlı fark yoktu ( $p>0.05)$. Grup-1 deki hastaların ortalama ağırlıkları $21.3 \pm 6.7 \mathrm{~kg}$ iken grup-2 deki hastaların ortalama ağırlıkları $19.7 \pm 5.4$ $\mathrm{kg}$ idi ve gruplar arasındaki ortalama hasta ağırlıkları anlamlı olarak farklı değildi $(\mathrm{p}=0.257)$. Tonsillektomi endikasyonları grup-1 deki hastaların 23'ünde (\% 62.1) rekürren tonsillit iken 14 'ünde (\% 37.9) obstriktif tonsil hipertrofisi idi. Grup-2 deki hastaların tonsillektomi endikasyonları ise 25 (\% 60.9) hastada rekürren tonsillit ve 16 (\% 39.1) hastada obstriktif tonsil hipertrofisi idi. Tonsillektomi endikasyonları açısından da gruplar arasında anlamlı bir fark saptanmamışıır (Tablo 1). Hastaların demografik ve klinik özellikleri Tablo 1'de sunulmuştur.

Tablo 1. Hastaların demografik ve klinik özelliklerinin karşılaştırilması

\begin{tabular}{llll}
\hline & $\begin{array}{l}\text { Koblasyon } \\
\text { tonsillektomi } \\
\text { grubu }\end{array}$ & $\begin{array}{l}\text { Bipolar } \\
\text { tonsillektomi } \\
\text { grubu }\end{array}$ & $\mathrm{P}^{*}$ \\
\hline Yaş (yıl) & $8.2 \pm 3.9$ & $7.9 \pm 4.1$ & $>0.05$ \\
$\quad$ Cinsiyet (n, \%) & $21(\% 56.8)$ & $22(\% 53.7)$ & $>0.05$ \\
$\quad$ Kadın & $16(\% 43.2)$ & $19(\% 46.3)$ & $>0.05$ \\
$\quad$ Erkek & $21.3 \pm 6.7$ & $19.7 \pm 5.4$ & 0.257 \\
Kilo (kg) & & & \\
$\quad$ Tonsillektomi Endikasyonu & $23(\% 62.1)$ & $25(\% 60.9)$ & $>0.05$ \\
$\quad$ Rekürren tonsillit & $14(\% 37.9)$ & $16(\% 39.1)$ & $>0.05$ \\
$\quad$ Tonsil hipertrofisi & $\mathbf{1 9 . 6 \pm 7 . 3}$ & $<0.001$ \\
\hline Ortalama ameliyat süresi (dk) & $\mathbf{2 8 . 4 \pm 6 . 1}$ & $\mathbf{1 9 . 6}$ \\
\hline${ }^{*} 0.05$ değerinin altındaki P değeri istatistiksel olarak anlaml kabul edildi
\end{tabular}

* 0.05 değerinin altındaki $P$ değeri istatistiksel olarak anlamlı kabul edildi

Gruplar arasında ortalama ameliyat süreleri karşılaştırıdığında koblasyon tonsillektomi $(28.4 \pm 6.1 \mathrm{dk})$ yapılan hastaların ortalama ameliyat süresi bipolar tonsillektomi $(19.6 \pm 7.3 \mathrm{dk})$ yapılan hastalara kıyasla istatistiksel olarak anlamlı derecede daha uzun idi $(p<0.001)$. Ameliyat sonrası 1 hafta boyunca günlük olarak Wong Baker görsel ağrı ölçeğine göre ölçülen ağrı şiddeti karşılaştırıldığında koblasyon tonsillektomi grubunda bipolar tonsillektomi grubuna kıyasla ameliyat sonrası birinci $(p<0.001)$, ikinci $(p=0.019)$ ve üçüncü $((p<0.021)$ günlerde anlamlı olarak daha az ağrı gözlendi. Ameliyat sonrası ilk 3 gün hariç 1 hafta boyunca diğer günlerde gruplar arasında ağrı şiddeti açısından anlamlı fark gözlenmedi (Tablo 2).

Tablo 2. Hastaların tonsillektomi sonrası morbiditelerinin gruplar arasında karşılaştırılması

\begin{tabular}{|c|c|c|c|}
\hline & $\begin{array}{l}\text { Koblasyon } \\
\text { tonsillektomi } \\
\text { grubu }\end{array}$ & $\begin{array}{l}\text { Bipolar } \\
\text { tonsillektomi } \\
\text { grubu }\end{array}$ & $P^{*}$ \\
\hline \multicolumn{4}{|l|}{ Postoperatif ağrı skoru } \\
\hline 1. gün & 4.37 & 6.72 & $<0.001$ \\
\hline 2. gün & 4.93 & 6.27 & 0.019 \\
\hline 3. gün & 3.84 & 5.83 & 0.021 \\
\hline 4. gün & 3.98 & 4.17 & 0.169 \\
\hline 5. gün & 2.37 & 2.51 & 0.091 \\
\hline 6. gün & 1.09 & 1.54 & 0.271 \\
\hline 7. gün & 0.17 & 0.91 & 0.314 \\
\hline \multicolumn{4}{|l|}{ Postoperatif kanama } \\
\hline Primer kanama & $2(\% 5.4)$ & $3(\% 7.3)$ & $>0.05$ \\
\hline Sekonder kanama & $3(\% 8.1)$ & $8(\% 19.1)$ & $<0.05$ \\
\hline Toplam & $5(\% 13.5)$ & $11(\% 26.8)$ & 0.034 \\
\hline \multicolumn{4}{|l|}{ Kanama kontrolü } \\
\hline Ameliyathane şartlarında & $1(\% 2.7)$ & $4(\% 9.7)$ & $>0.05$ \\
\hline Konservatif yaklaşımla & $4(\% 10.8)$ & 7 (\%17.1) & $>0.05$ \\
\hline
\end{tabular}

Grup-1'de ameliyat sonrası 2 (\% 5.4) hastada primer ve 3 (\% 8.1) hastada sekonder kanama olmak üzere toplam 5 (\% 13.5) hastada tonsillektomi sonrası kanama izlenmiştir. Grup-2' de ise toplam 11 (\% 26.8) hastada ameliyat sonrası kanama izlenmiş olup bunların 3'ü (\% 7.3) primer 8'i (\% 19.1) sekonder kanama idi (Tablo 2). Ameliyat sonrası gözlemlenen toplam kanama oranı koblasyon tonsillektomi yapılan grupta bipolar tonsillektomi yapılan gruba kıyasla anlamlı derecede daha az idi $(p=0.034)$. Grup-1 de gözlemlenen kanamalı olguların sadece 1 (\% 2.7) tanesinde kanama kontrolü için ameliyathane şartlarında müdahale gerekti kalan diğer 4 hasta hastaneye yatış ve oral alım kısıtlanması, intravenöz hidrasyon, soğuk gargara, gümüş nitrat ile koterizayon ve baş elevasyonu gibi konservatif yaklaşımlarla takip edildi. Grup-2 de ise $4(\% 9.7)$ hastaya kanamayı durdurmak için ameliyathane şartlarında genel anestezi altında ligasyon ve plika sütürasyonu gerekti, diğer 7 hastada ise hastaneye yatış yapılarak ve konservatif yaklaşımlar uygulanarak kanama kontrolü sağlandı. Kanama kontrolü sonrası serviste 1 gün boyunca takip edilen hastalar kanama gözlenmemesi üzerine taburcu edildiler. Her iki grupta da hiçbir hastaya oral alım bozukluğu ve dehidratasyon nedeni ile hastaneye yatış gerekmedi.

\section{Tartışma}

Tonsillektomi kulak burun boğaz pratiğinde sıklıkla çocuk hastalarda olmak üzere hem çocuk hem de erişkin hastalarda yapılan en sık cerrahi işlemlerden birisidir (2). Teknolojik ilerlemelere paralel olarak geliştirilen diot lazer, termal welding, bipolar, koblasyon ve plazma bıçağı gibi farklı yeni nesil cerrahi cihazlarla tonsillektomi ameliyatı yapılmaktadır $(1,4,5,8)$. Bu teknolojik gelişmelere rağmen tonsillektomi sonrası kanama ve ağrı halen en sık karşıla- 
şılan komplikasyonlar olmaya devam etmektedir. Bu çalışmada son zamanlarda giderek artma eğiliminde olan koblasyon tonsillektomi ve daha yaygın uygulanan bipolar tonsillektominin cerrahi sonuçları karşılaştırı mışır.

Tonsillektomi sonrası ağrı ameliyat sonrası gözlemlenen, hayat kalitesini düşüren, uzamış analjezik kullanımına neden olan ve özellikle çocuk hasta grubunda oral alım bozukluğuna sekonder hastane yatışı gerekitirecek kadar dehidratasyona neden olabilen sık karşılaşılan bir morbiditedir. Bu çalışma ameliyat sonrası ağrı bakımından koblasyon tonsillektominin ameliyat sonrası ilk 3 günde bipolar tonsillektomiye kıyasla istatistiksel olarak anlamlı daha düşük ağrı seviyeleri ile ilişkili olduğunu ortaya koymuştur (Tablo 2). Polites ve ark. tarafından yapılan koblasyon ve bipolar tonsillektomiyi karşılatıran çalışmada tonsillektomi sonrası ağrı skorları koblasyon grubunda anlamlı derecede daha az olarak bildirilmiştir (1). Benzer şekilde Noordzij ve Afflec tarafından yapılan ve koblasyon ve monopolar elektrokoter tonsillektominin sonuçlarını karşılaştıran çalışmada koblasyon tekniğinin daha az ağrıya neden olduğu belirtilmiştir. Koblasyon tonsillektominin geleneksel bipolar ve monopolar koter tonsillektomisine kıyasla ameliyat sonrası daha az ağrıya neden olması koblasyon sisteminin daha düşük yüzey sıcaklığında çalışmasıyla (40-60。) ve etraf dokuya daha az termal hasar vermesiyle ilişkisi olabilir. Bipolar ve monopolar gibi yaygın olarak kullanılan ve diğer radyofrekans teknolojisiyle çalışan geleneksel elektrocerrahi cihazların kontrolsüz ve çok daha yüksek yüzey sıcaklıklarında (100-300 ) çalışarak komşu dokularda ciddi termal hasar meydana getirdikleri yapılan çalışmalarda ortaya konulmuştur (9). Koblasyon cihazı ile ameliyat edilen hastalarda normal dokuya ISI enerjisi penetrasyonu $1100 \mu \mathrm{m}$ iken bu penetrasyon derinliği geleneksel elektrocerrahi cihazlarda $2200 \mu \mathrm{m}$ olup iki katı kadar fazladır (10). Aktif uc kısmındaki kontrollü radyofrekans akımıyla ve uc kısımdaki dahili yıkama sistemi ile oluşturulan plasma alanı koblatör cihazının çok daha düşük yüzey sıcaklıklarında çalışmasına ve sağlıkı dokuya çok daha az ısı enerjisi geçişine olanak verir; böylece cerrahi alanda minimal ISI travması ve ameliyat sonrasında da daha az ağrı sağlanmış olur.

Tonsillektomi sorası kanamalar çoğunlukla minör kanamalar olup konservatif yaklaşımlarla kendiliğinden durmaktadır ancak nadirende olsa hayatı tehdit edebilecek şiddette tonsil kanamaları bildirilmiştir (11). Literatürde primer kanamaların sekonder kanamalardan daha fazla olduğu yönündeki çalışmalara karşın aksi yönde sekonder kanamaların daha sık gözlemlendiğini bildiren çalışmalar mevcutur $(11,12)$. Bu çalışmada sekonder kanama oranları hem koblasyon hemde bipolar tonsillektomi grubunda primer kanama oranlarından daha fazla idi. Wiltshire ve ark. yapımış oldukları çalışmada, ameliyat sonrası kanama oranı açısınıdan koblasyon ve bipolar tonsillektomi arasında anlamlı derecede bir fark saptamamışlardır $(p=0.966)$ ve hiçbir hastada kan transfüzyonu gerektirecek şiddette kanama bildirmemişlerdir (4). Aksine, bu çalışmada koblasyon tonsillektomi yapılan grupta ameliyat sonrası primer kanama oranları arasında gruplar arasında anlamlı bir fark gözlenmezken, sekonder ve toplam kanama oranlarına bakıldığında koblasyon tonsillektomi grubunda bipolar tonsillektomi grubuna göre anlamlı derecede daha az kanama gözlenmiştir (Tablo 2). Her iki gruptada kan transfüzyonu gerektirecek şiddette kanama gözlenmedi ve gruplar arasında kanama kontrolü için tekrar ameliyata alınan hastaların oranı bakımından anlamlı fark saptanmadı (Tablo 2). Öte yandan Lane ve ark. yaptıkları çalışmada yine koblatör cihazı gibi radyofrekans ile çalışan plazma bıçak cihazının tonsillektomide ameliyat sonrası kanama açısından koblatör cihazından daha üstün olduklarını bildirmişlerdir (8). Tüm bunlara ek olarak soğuk teknik diseksiyon tonsillektominin intraoperatif kanamanın fazla olması ve sıcak tekniklere kıyasla daha uzun ameliyat süreleri gibi dezavantajları olmasına rağmen, literatürde tonsillektomi için soğuk diseksiyon tekniğinin ve kanama kontrolü için ligasyonun ve sütürasyonun halen ameliyat sonrası kanama için en güvenli cerrahi teknik olduğu bildirilmiştir (13).

Daha yüksek sıcaklıklarda çalışan bipolar tonsillektomi işleminde daha hızlı doku diseksiyon sağlar dolaysıyla bipolar tonsillektomi ortalama ameliyat sürelerinin daha düşük Isı enerjisi ile çalışan koblatör cihazı ile yapılan tonsillektomi ameliyat sürelerinden daha kısa olduğu bildirilmiştir (4). Bizim çalışmamızda benzer şekilde koblasyon tonsillektomi grubunda ortalama ameliyat süresi bipolar tonsillektomi grubunun ortalama ameliyat süresine kıyasla istatistiksel olarak anlamlı derecede daha uzun idi (Tablo 1). Koblatör cihazının aktif ucu tek kullanımlık olmasına rağmen tekrar steril edilebilir özelliktedir, ancak ortalama 10-15 kullanımdan sonra koblasyon ve ablasyon yapan aktif uç deforme olmaktadır. Bipolar ise çok yaygın ve çok daha ucuz maliyetli bir cihazdır ve her işlem sonrası steril edilebilip tekrar kullanılabilir. Maliyet etklinliği açısından bipolar tonsillektominin koblasyon tonsillektomisine göre çok daha avantajlı olduğu öngörülebilir.

Sonuç olarak daha uzun ameliyat sürelerine neden olan ve daha maliyetli bir teknik olmasına rağmen, ameliyat sonrası anlamlı derecede daha az ağrı ve kanama oranları ile azalmış morbidite sağlayan koblasyon tonsillektomi tekniği yaygın olarak kullanılan bipolar tonsillektomiye makul bir alternatif olabilir.

\section{Açıklamalar}

Yazar herhangi bir çıkar çatışması beyanı bildirmemektedir.

Çalışmaya finansal olarak katkı sağlayan herhangi bir kurum ya da kişi bulunmamaktadır 


\section{Kaynaklar}

1. Polites N, Joniau S, Wabnitz D, Fassina R, Smythe C, Varley $P$ et al. Postoperative pain following coblation tonsillectomy: randomized clinical trial. Aust N Z J Surg. 2006;76:226-9.

2. Çakır $A$, Boran $C$, Olgun $Y$, Erdağ TK. Tonsillektomi sonrası kanama: 10 yıllık deneyimimiz. Kulak Burun Bogaz Ihtis Derg. 2017;27(1):1-9.

3. Tuchtan L, Torrents J, Lebreton-Chakour C, Niort F, Christia-Lotter MA, Delmarre $E$, et al. Liability under post-tonsillectomy lethal bleeding of the tonsillar artery: a report of two cases. Int J Pediatr Otorhinolaryngol. 2015;79:83-7.

4. Wiltshire D, Cronin M, Lintern N, Fraser-Kirk K, Anderson S, Barr R, et all. The debate continues: a prospective, randomised, single-blind study comparing Coblation and bipolar tonsillectomy techniques. J Laryngol Otol. 2018;132(3):240-5.

5. Elbadawey MR, Hegazy HM, Eltahan AE, Powell J. A randomised controlled trial of coblation, diode laser and cold dissection in paediatric tonsillectomy. J Laryngol Otol. 2015;129(11):1058-63.

6. Temple R, Timms M. Paediatric coblation tonsillectomy. Int J Pediatr Otorhinolaryngol. 2001;61:195-8

7. Stoker K, Don D, Kang R, Haupert M, Magit A, Madgy D. Pediatric total tonsillectomy using coblation compared to conventional electrosurgery: a prospective, controlled, single-blind study. Otolaryngol Head Neck Surg. 2004;130:666-75

8. Lane JC, Dworkin-Valenti J, Chiodo L, Haupert M. Postoperative tonsillectomy bleeding complications in children: A comparison of three surgical techniques. Int J Pediatr Otorhinolaryngol. 2016;88:184-8

9. Stalder KR, Woloszko J, Brown IG, Smith CD. Repetitive plasma discharges in saline solutions. Appl Phys Lett. 2001;79:4503-5

10. Woloszko J, Stalder KR, Brown IG. Plasma characteristics of repetitivelypulsed electrical discharges in saline solutions used for surgical procedures. IEEE Trans Plasma Sci IEEE Nucl Plasma Sci Soc. 2002:30:1376-83

11. Østvoll E, Sunnergren O, Ericsson E, Hemlin C, Hultcrantz E, Odhagen E, et al. Mortality after tonsil surgery, a population study, covering eight years and 82,527 operations in Sweden. Eur Arch Otorhinolaryngol. 2015;272:737-43.

12. Windfuhr JP, Verspohl BC, Chen YS, Dahm JD, Werner JA. Posttonsillectomy hemorrhage-some facts will never change. Eur Arch Otorhinolaryngol. 2015;272:1211-8.

13. Lowe D, van der Meulen J, Cromwell D, Lewsey J, Copley L, Browne J, et al. Key messages from the National Prospective Tonsillectomy Audit. Laryngoscope. 2007;117:717-24 